\title{
EXCAVATIONS AT GRIME'S GRAVES DURING 1917.
}

\author{
By A. E. PeAKe, M.R.C.S., L.R.C.P. \\ Read at Saffron Walden, February 11th, 1919.
}

In 1917 the work at Grime's Graves was carried out by Mr. and Mrs. E. T. Lingwood and myself, and was limited to sections and floors, as the war prevented us from obtaining outside labour. For permission to excavate, we are again much indebted to the Trustees of the Weeting Estate, Mrs. T. S. Hall and Mr. C. Cockburn. The following paper gives the results of the work, and in it are figured some of the new implements.

The Grime's Graves culture shows a wide variety of forms, and I think it is important to illustrate as many of these as possible. This vast factory must have sent out implements far beyond the present boundaries of Britain, and no doubt many implements found on the Continent will be traced to this source. Very few industries have been sufficiently illustrated in the past, and this has led to erroneous conclusions when collections are not accessible.

The series selected for illustration in the present paper add a number of new forms to those already figured in previous numbers of these Proceedings, and in the Report of the work of 1914, and emphasise the great variety of forms made in this culture. The list is not yet complete. It is essentially a flake industry, the flakes being worked up into implements. The broken L.evallois flake is, however, far and away the commonest piece made on this site.

I might in passing enter a plea for the standardisation of the nomenclature of implements. A definition of such terms as handaxe and Cissbury type, for instance, is badly wanted, and a Society such as ours might well take steps in the matter.

The present culture has received no recognition on the Continent, nor in recent works on pre-history, and the position of the Grime's Graves culture still remains a problem, which becomes still more complicated by the present record of pottery referred by Mr. Reginald Smith, F.S.A. to the Early Iron Age, in an undisturbed pit with a thick layer of Grime's flint refuse above it. The evidence in favour of a date near to the Abri Audi stage is considerably strengthened by the present additions to the flint discoveries, but the analogies and the method of their manufacture point far nearer to Mousterian than Aurignacian. It is singular that no parallel site where the Mousterian method is used and the Levallois flake manufactured has been recorded, either in this country or on the Continent, referable to the Neolithic age. It is quite certain that writers like Prof. Osborn can no longer say that the coup-de-poing was not made after early cave times, if Grime's Graves is of Neolithic date, and it is equally significant 
that the large Levallois flakes and flake implements of the Northfleet type, which were the main implements made at the Graves, are not recorded from the surface, and occur mainly in the gravels and brickearths. The question arises, were most of the Levallois flakes of Palæolithic date made at the factory at Grime's Graves ? The enormous output from this mine must be somewhere, and was probably widely distributed by barter even as far as the Continent.

The Moustier parallels from the Graves form an ever-growing list, to which I have added in this paper. We have also to record forms generally regarded as Neolithic celts, but jt must be remembered that this type is now recorded from brickearth and gravel. (e.g. Colyer's Pit, Milton St., Swanscombe, and Farnham, Surrey.) These celts are rare at the Graves, and in this respect the site differs from that of Cissbury and its nearer ally at Cranwich. The relatic nship of both the latter sites and that of Peppard has not yet been discussed in view of the new discoveries, and it would be premature to do so until some spadework has been done at Cranwich and the bulk of the Cissbury output has been described. Beyond the celts very few of the Cissbury implenents have been described and figured.

There can be no doubt that if a mine had not been below, Grime's Graves would be accepted from its flint evidence as an open-air station of late Moustier or early Aurignac date, many parallels of which are recorded from the Continent. A few of the implements might have been copied from Moustier ones, but the majority are rougher copies with a facies of their own. The newly-discovered open stations of Aurignac and Moustier date described by Mr. J. Reid Moir, at Ipswich, definitely establish the occurrence of superficial floors of cave date in this country, a fact long recognised on the Continent. This definitely disposes of the axiom so long held here that superficial floors such as we have described from 'Grime's Graves are necessarily Neolithic. The Bolton and Iaughlin floors too establish the fact of pottery and the modern type of man in Moustier times, and both of these facts accord with the discoveries at Grime's Graves.

The mixed character of the implements found at Grime's Graves would probably be explained in a cave if found together as the intermingling of several culture levels, and one is tempted to say that at Grime's Graves we have three levels of culture, Moustier, Aurignac, and Neolithic. Such an explanation is precluded, however, by the fact that the floors lie above the chalk and sand thrown out from deep shafts which lead down into the old flint mine, and must of necessity be later, and the whole output is linked up by the facetted platform and the Northfleet method of work. The key to the problem lies still in a thorough examination of the galleries and work on parallel sites. It must not be lost sight of that in 1914 we found certain blocks of chalk carved in the round.

At present both schools of opinion, Palæolithic and Neolithic, are faced with facts which cannot be reconciled 
Messrs. A. S. Kennard, F.G.S., and B. B. Woodward, F.L.S., have kindly identified the shells obtained from sections in two new pits, and have expressed the opinion that these are contemporary with those previously excavated.

In the work in 1917 we defined the limits of floors 15 and 16 which have yielded us such a wealth of implements, made sections across two new pits (pits 3 and 4), and also others in the field North of the Graves, which chowed that the plough had cut into an old level and mixed up the chipped material with the boulder clay beneath and the sand above. This would account for the numbers of implements strewn over the surface in that direction. Another section made in the field about a mile West of the plantation, near Botany Bay cottages, showed no floors. The zone of chipped pieces of Grime's Graves date must therefore have been a ploughed-up floor. A section was also made in the side of a pit North of Pit 1, and this is called floor 29. Floor 11 was reinvestigated.

The occurrence of gravers led us to look out for carving in chalk and inscribed pieces of bone or flint crust, and I was fortunate in finding an external flake with the rough outline of a fish engraved on it.

\section{Re-examination of Floor XI.}

Originally discovered in 1914, a record of the principal pieces found there is to be seen in the "Report" 1914 . It was a coarselychipped zone (Class I), and the refuse on it was scanty and quite superficial, lying in the chalk rubble. The 1914 work established its identity with the other floors from the presence of flake implements with the facetted platform. The enthusiastic helpers who dug over some of the floors missed a good deal owing to lack of knowledge, and I have found a re-examination yielded good results. On cutting into this floor I found it lay on a mass of sand not in situ, as beneath lay boulder clay resting on chalk rubblc. In the sand $2 \mathrm{ft}$. below the floor, i.e. $3 \mathrm{ft}$. below the present surface, I found a small area $1 \times 2 \mathrm{ft}$. of charcoal and burnt sand, evidently a cooking hearth, though no bones lay there. In the sand round the hearth a few interesting chipped pieces occurred.

Fig. 13 (A). A well-finished implement which may be called a hand-axe or racloir ( 3 by $2 \frac{1}{2}$ in.), patinated white, and stained with manganese. It is made from a Levallois flake. The upper face shows truncated impressions, and bears evidence of having been struck from a tortoise core. It is trimmed also round the edge, the under face having the bulb entirely worked away. The rest of the face is not worked, and its margin shows signs of use.

Fig. 13 (B). A long ridged flake with facetted platform and much battering above the bulb to thin the handle, this end being squarcd. The right margin is steeply worked, and in its centre has a double encoche with a spur between the notches. The left margin is sharp, and bears signs of use, and the end is partly a hinge fracture. The upper face of the end is finely worked diagonally, suggesting 
the burin laterale. It is thus a combined knife and scraper ( $5 \frac{1}{2}$ by $2 \frac{1}{2}$ in.).

Two heavy partly-crusted flakes from this floor are interesting.

Fig. 13 (c). ( $4 \frac{3}{2}$ by 3 ) A racloir, the whole of one side being trimmed on the under face with stepped, scaled work, the other edge
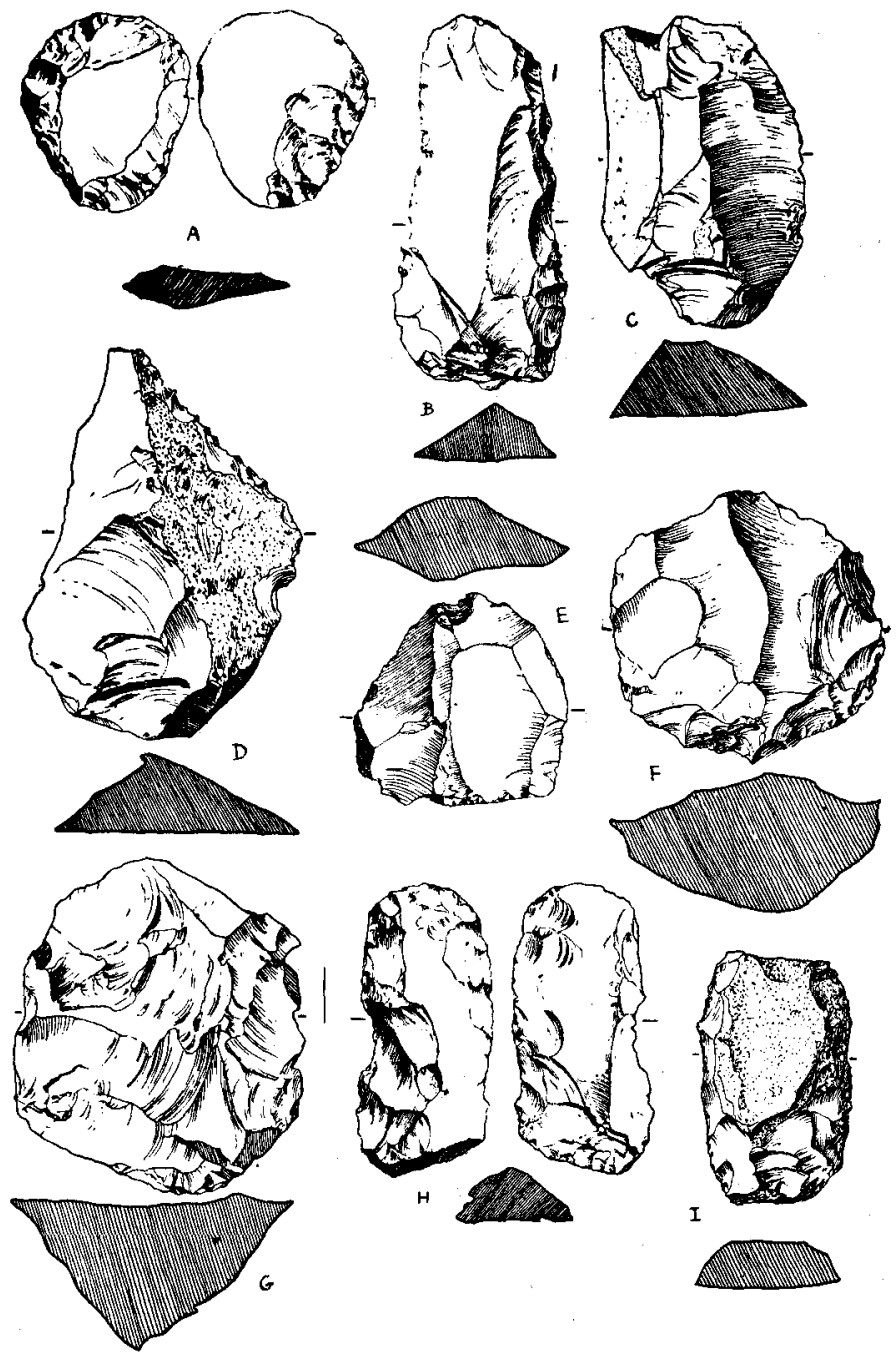

Fig. 13. (A) Handaxe. (B) Knife-burin. (c) Racloir with facetted platform. (D) Saw with facetted platform. (E) Implement made from Tortoise core. (F) Tortoise core. (c) Tortois s core. (H) Celt-like implement. Floor XI. A.E.P. (I) Celt-like implement with end missing. Floor XV. E. T. Lingwood. $\frac{1}{4}$. 
retaining crust. The platform is facetted. The scale work is typically Mousterian in technique.

Fig. 13 (D). (6 by $3 \frac{7}{8}$ ) This is clearly a saw. The platform has two facets, the end being diagonal and coarsely engrailed, and the sides parallel. It is an external flake.

Fig. 13 (E). A triangular implement of drift form, has a sharp convex used end with a small encoche at the corner. It is well chipped onboth faces, the under one bearing evidence that it is made from a small tortoise core. The Levallois flake struck from it is only $2 \frac{1}{2}$ inches long. Many such flakes came from floor 28, and bore signs of use ( $3 \frac{1}{4}$ by $3 \frac{1}{4}$ in.).

Fig. $13(\mathrm{~F})$. A typical tortoise core found buried in the sand, patinated blue. The under face is covered with crust, and is naturally boat-shaped, the edge being worked steeply all round. The upper face bears many scars, but none of the detached flakes would be of any use. Probably this face is dressed ready for a final blow. ( $4 \frac{1}{2}$ by $3 \frac{3}{4}$ in.). At one part the edge is squared and finely worked, and the piece seems to have been used as an implement.

Fig. $13(G)$. Another fine example of a typical tortoise-core still capable of having a Levallois flake $4 \frac{1}{2}$ inches long struck from it. It is chipped to form a keel below, and dressed on the upper face.

Fig. 13 (H). A celt-like implement of the same form as fig. 48, Proc., Vol. 2, $4 \frac{1}{2}$ in. long. One face is much flatter, and both are worked; sides parallel; end convex with angular and convex corners. It is made from a large flake. We have now six other examples of this type. I figured a similar form from Peppard Proc., Vol. I, pl. 4, and Mr. G. Worthington Smith records the form from a floor at Hertford.

\section{RE-examination of Floors 15 and 16.}

The dimensions of floors 15 and 16 had not been reached in our former work, and we extended the edge of the excavation to reach the limits of these zones. Mr. Lingwood too made a series of radiating trenches round floor 15 , and found the ground for the most part unproductive, thus defining this zone floor 15, and proving it to be a chipping centre.

Floor 15 was a most prolific site, and later on it is proposed to figure together all the pieces from this and floor 16 and compare them with the rest of the culture, from which they differ considerably. A large number of fine pieces from both these floors are not yet figured, and when it is remembered that I have over 100 scrapers, a large proportion of which are from these two floors, it will be realised how much material there is to describe before the whole culture can be estimated. I shall confine myself in the present paper to the pieces found in the present year,

FLOOR 15.

Fig. 14 (A). This axe scraper is one of the finest finished implements found at the Graves (E. T. Lingwood). It is a onefaced implement made from a Levallois flake trimmed all round 
the edge. It may be described as triangular in form, with a blunt, narrow end, and a convex broad end with rounded angles (4 by 3 in.). Two implements of this form were found in 1914, and another from floor 15 was figured Proc., Vol. 2, Pt. 3, but none of these were so finely finished. It is a link between the axes and end scrapers.
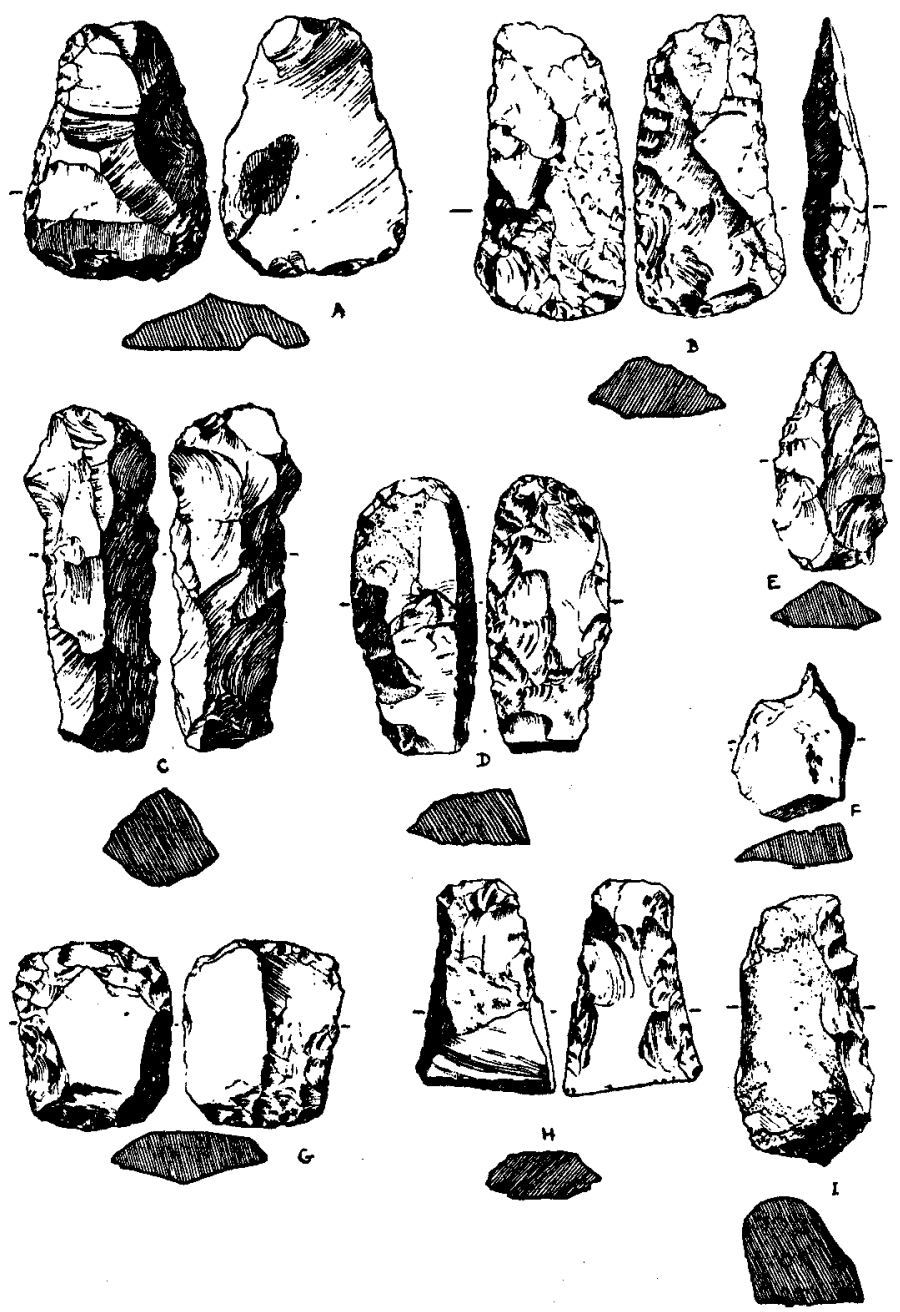

Fig. 14. (A) Axe-racloir (E.T.L.). (B) Celt (A.E.P.). (c) Pick with point missing. (D) Celt-like implement. (E) Pointed implement of Le Moustier form. (E.T.L.). (F) Borer of "Cave" Form. (c) Small Axe (A.E.P.). All Floor XV. (H) Implement resembling tranchet of the Danish kitchen middens. Floor XXVIII. (A.E.P.). (I) Steepsided plane used as a hammer. Floor XV. (E.T.L.). $\frac{1}{4}$ 
Fig. 14 (B). Another complete implement (A.E.P.) of the Neolithic celt class ( $4 \frac{1}{2}$ in. long). It has a pronounced twist. Both faces are worked all over, and the edges finely finished off. The flaking is diagonal to the edge, and tends to fan work. The broad end is functional, one corner being more angular. Blue and white two-sided patination. It came from the soil above the floor.

Fig. 14 (C). A long celt (5-in. long) (E.T.L.) of triangular section with parallel side edges of a type known now to have been made at the Graves, resembling the Thames pick. An example was figured Proc., Vol. II., pl. 3, fig. 81 k. The faces are steep with a ridge down the centre, and one side is finely worked from the base. Neither end in its present condition would be of use, and it is probably a failure.

Fig. 14 (D). Two-sided patination. Another celt-like form made from an external flake (E.T.L.) (4 in. long). The peculiarity of this implement is that the work is mostly on the flake surface, only one side edge being worked up the crusted face (blue patination).

Fig. 13 (I). A celt-like implement with the cutting end missing (E.T.L.). It is made from a crusted flake with facetted butt with the sides steeply trimmed. The broken end has a flake taken out of the bulb face, which spoils the symmetry. It closely resembles fig. 83 F., Proc., Vol. 2 (blue and white).

Fig. 14 (E). A sharp-pointed implement of triangular Mousterian form. It is made from a ridged flake, and the point is formed by secondary work on the side edges, limited to one edge in each face in a manner most suitable for boring. The sides are roughly trimmed, as is also the butt, which has a rounded and angular corner. (E.T.L.) Blue and white patina ( $3 \frac{1}{4}$ in.).

Fig. $14(F)$. A borer with delicate point worked at the sides and not on the flake surface. It is made from wall flint which has lain on the surface long enough to patinate white, as part of the unchipped portion shows. Platform plain (21 in. long). Mr. H. Balfour, F.S.A., pronounced this to be cave-like in form. (A.E.P.)

Fig. 14 (G). A square implement which might be classed with the axes (A.E.P.). One end is trimmed on both faces to form a slightly convex edge. It is made from a ridged flake, and the peculiarity lies in the secondary work being done entirely on the bulb face except at the cutting end. Patinated blue ( $2 \frac{3}{4}$ by 21 in.).

Fig. 15 (A). A long implement made from an external flake. The broad end is chipped on both faces, and its convex end suggests that it was used as a celt, probably hafted. There are signs of use along the sharp side edge, and it may also have been used for cutting or scraping (E.T.L.).

Fig. $14(\mathrm{H})$. A triangular implement strongly resembling the tranchet axe of the kitchen middens of Denmark. It is made from an external flake, and like several examples of this type from Denmark in Dr. Sturge's collection, and in the Pitt Rivers Museum, Oxford, shows work on the flake face done from the side. The 

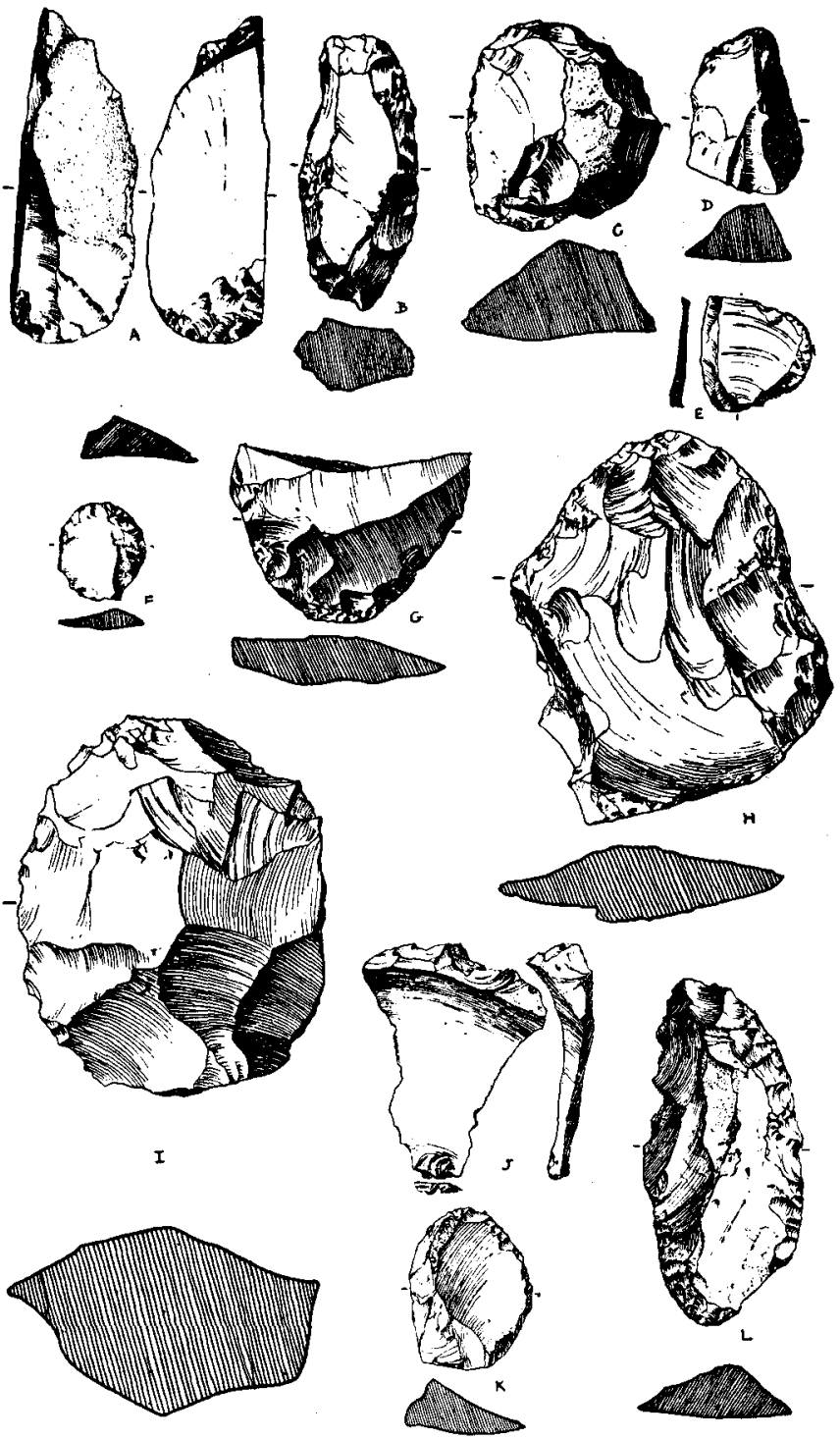

Fig. 15. Floor XV. (A) Celt-like Implement. (B) Long racloir with steep edge. (c) Massive scraper of Le Moustier-Aurignac form (E.T.L.). (D) Aurignac type of scraper. (A.E.P.) (E) Thin scraper with fine fan-shaped work. (F) Rare form of end-scraper. (c) Flake implement of Northfleet type (E.T.L.). (H) Handaxe of Drift form (A.E.P). Floor XVI. (I) Large implement of Northfleet form, probably a chopper. (J) Plunging flake implement with facetted platform. (k) Le Moustier point. (L) Double racloir of Le Moustier form (A.E.P.). 
broad end shows a transverse facet and a sharp edge, which is, however, unused, and it must be regarded as a small axe used at the narrower convex end (A.E.P.) (Floor 28). The tranchet edge is probably accidental and the implement originally longer.

Fig. 14 (I). A fine example of a steep-sided plane used also as a hammer, made from part of a crusted nodule (patinated white) (E.T.L.). It is made with a minimum of work. (4 in. long).

Ffg. 15 (B). A plane, or perhaps a racloir, of the same form as the last. It has the flattened base and convex steep side of Fig. $14(\mathrm{H})$. In addition it has one end sharply pointed (part of the work being later as it shows a blue patina on the otherwise white surface), and the other steep and convex. The other side margin is much undercut and battered. The battering is seen over much of this steep side, and also on the ridges of the upper face, and the piece has evidently been used either for hammering or as an anvil (E.T.L.) (4 in. long).

Fig. 15 (c). A massive ear-shaped scraper made from a crusted flake (E.T.L.) trimmed all round the edge except at the butt, which is thinned on its upper face. This is an example of transitional work. Its size and massiveness point to Moustier, and its steepness to Aurignac ( $3 \frac{1}{4}$ by 3 in.). Two-sided patina, blue above, unpatinated below.

Fig. 15 (D). A scraper of true Aurignac type made from an external flake. The fine secondary work is confined to the end, which has a broad, rounded nose. Platform plain (21 in. long). Similar scrapers are figured by Sollas (Ancient Hunters) from La Coumbadel-Bouitou (Corrèze) (fig. 139), and Osborn (Men of the Old Stone Age), fig. 150.

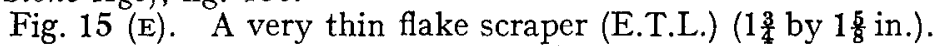
The side projects and is chipped to form a convex scraping edge. The work is done by pressure, and is fan-shaped. This delicate work is very rare from the Graves, and a piece like this, which might well be quite late, especially coming from floor 15 where a hearth was inserted, makes one think that there are two cultures at the Graves.

Fig. 15 (F). A small round-ended scraper with fine pressed fan work and plain platform, $\mathbf{1} \frac{3}{8}$ in. long (blue and white patina) (E.T.L.). This is a very rare form from this site, and a great contrast to the massive pieces from the Graves.

Fig. 15 (G). The butt end of a fine flake implement of the Northfleet type (E.T.L.) ( $2 \frac{1}{2}$ by $3 \frac{3}{4}$ in.). Part of the end of the implement is left, and the length was $3 \frac{1}{2}$ inches. The upper face shows the long primary impressions of work done on the tortoise core. One side edge is dressed on both faces to make it symmetrical. The butt shows two facets on the platform and two bulbs. The complete implement would be a short ovate, broader and shorter than fig. 77, G. G. Report, but of the same type.

Fig. 15 (H). A massive, pointed, flattened implement of unmistakably Drift type with the butt left rough. The butt is much battered in places in an attempt to complete this half of the 
implement, but the flint has proved intractable. It is of the same type as fig. 415 (Evans, Ancient Stone Implements) from Biddenham, and a larger and rougher edition of fig. 413 from Wookey Hole (som.). Patinated white (A.E.P.).

FIOOR 16.

This floor has already been described in former papers. Mr. Lingwood cut sections between this and floor 15, and found they were separated by a sterile interval. The following new implements are worth recording.

Fig. 15 (I). A heavy piece which has the outline of a thick, pointed Drift implement with a cutting edge all round, of a type occurring at Northfleet, and distinct from the tortoise cores. One side edge is very steep and may be intended for the hand, in which case the other edge of regular, convex, wavy margin may be

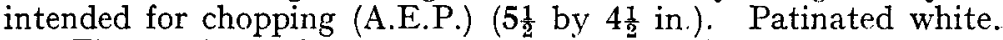

Fig. $15(\mathrm{~J})$. A fine example of a "plunger" which retains part of the dressed under-face of the core. The platform is delicately facetted ( $3 \frac{1}{2}$ in. long), unpatinated (A.E.P.).

Fig. 16 (A). An implement like a handaxe, made from an external flake (E.T.L.). Both faces are dressed, but the point is left untouched, and seems too slender for use. Fine secondary work is carried along one side, and I regard it as a racloir. Twosided patination, white below and blue above (E.T.L.) ( 4 by $3 \frac{1}{2}$ in.).

Fig. 15 (L). Double racloir (A.E.P.), faintly blue. It is made from a flake $5 \frac{1}{4}$ in. long, and three parts of the edge is finely worked to form a convex scraper. The other end forms a blunt worked point, the flaking extending down the other side edge. Scratches are seen in the crust. It is essentially a left-handed implement.

Fig. 16 (B). An irregular scraper with steep work at the end and side, leaving a beak-like process between. The butt is finely flaked on the upper face, and trimmed below to remove the butt. Unpatinated ( $3 \frac{1}{4}$ by $2 \frac{3}{4}$ in.) (A.E.P.).

Fig. 15 (K). A "pointe" of Moustier type, with plain platform, unpatinated (A.E.P.) (2 $\frac{1}{2}$ in. long).

Fig. 16 (c). A double racloir or "pointe" made from an external flake with plain platform. Its thickness suggests transition to Aurignac ( $2 \frac{1}{4}$ in. long.) Blue patination (A.E.P.).

Fig. 16 (D). A massive racloir " pointe" showing steep work pointing to Aurignac influence. Slightly facetted platform. Handle thinned on upper face. The steep margin engrailed. It is a composite tool combining the racloir and perhaps the saw with a sharp, strong point (A.E.P.) ( $4 \frac{1}{4}$ by $2 \frac{3}{4}$ in.).

Fig. $16(\mathrm{E})$. A steep end scraper with side edge dressing and bulb trimmed away, with a sharp and a rounded corner at the end. Faintly blue ( $2 \frac{1}{2}$ by 2 in.) (A.E.P.). This is a typical Aurignac piece.

Fig. 16 (F). A unique square scraper, unpatinated (A.E.P.) ( 2 by 2 in.). The edges are battered and the flaking is not carried. up the face. 

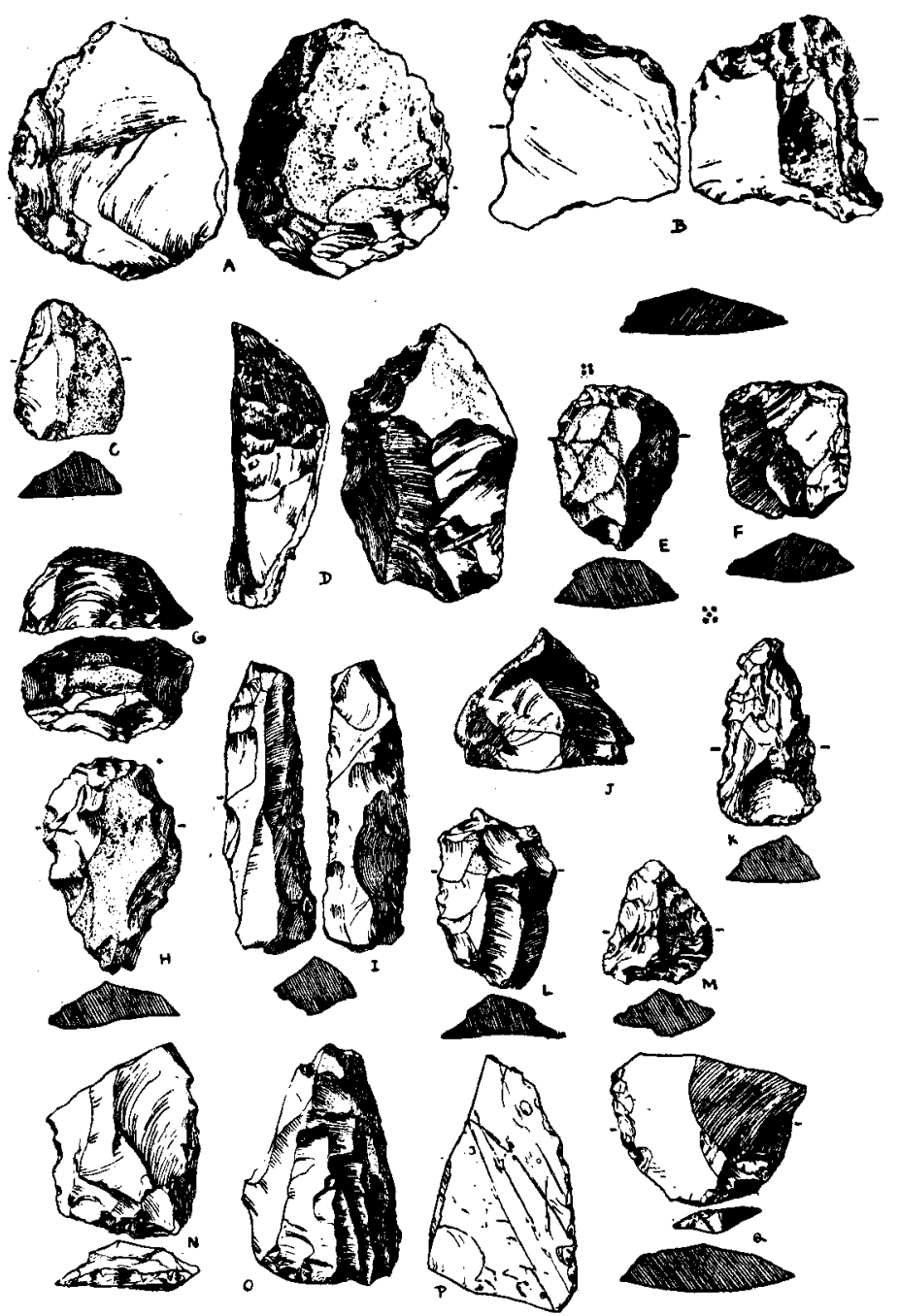

$\therefore$
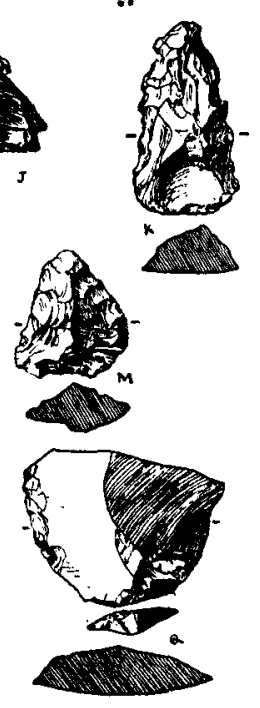

Fig. 16. Floor XVI. (A) Massive racloir (E.T.L.). (B) Beaked scraper. (c) Le Moustier pointe. (D) Massive racloir with facetted platform. (E) Aurignac type. (F) Straight-ended scraper with parallel dressed sides. (c) Carinated plane, (H) Pear-shaped end-scraper. (I) Narrow pick. (J) Tarté cone. (k) Pointed triangular flake with dressed sides. (L) Spurred end-scraper with dressed sides (A.E.P.). (M) Miniature handaxe (E.T.L.). (N) Levallois flake (broken) (A.E.P.). Floor XXIX. (o) Core plane. (P) Crusted flake with incised lines which form the rude outline of a fish. Pit 3. (Q) Butt end of used flake-implement of Northfleet type with facetted platform (A.E.P.). $\frac{1}{4}$ 
Fig. $16(G)$. A carinated double-ended plane (A.E.P.) (23 in. long). Sides and ends steeply worked with fine finishing retouch, especially to two spurs. The base is flat and part of it ha as number of incipient cones, suggesting that it was used at some time as an anvil. The base has one flake taken out from the end later than the edge work, which makes it resemble a small tortoise core. Unpatinated.

Fig. 16 (I). A rare piece of diamond section which resembles a long narrow pick, the point of which has gone. Unpatinated. The pointed end was evidently functional, as the butt is battered, and there is there no attempt to form a cutting edge (A.E.P.) $\left(4 \frac{1}{2}\right.$ in. long).

Fig. $16(\mathrm{~J})$. A rough Tarté cone with smooth base and convex undercut end, finished with fine secondary retouch. As is often seen with Aurignac cones, the back is left with crust. Blue-white

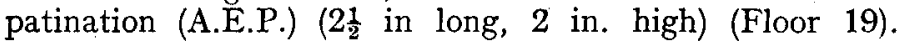

Fig. $16(\mathrm{k})$. A triangular implement with the work entirely on one face, made from a flake. It may be described as a "pointe" with complete side dressing and spurs, and the butt trimmed to form a convex border. The point curves to one side. Its characteristics suggest Mousterian and Aurignac influence (A.E.P.) white (3 in. long). (Floor 19).

Fig. 16 (L). A medium-sized scraper (Floor 21) (E.T.L.) trimmed along the side to form a convex racloir edge. The end has a delicate spur turned to one side, and between this and the racloir side is finely-worked squared border (E.T.L.) patinated white (2⿺ in. long).

Fig. $16(\mathrm{M})$. A remarkable little implement ( 2 by $1 \frac{8}{8}$ in.) which is chipped on both faces and resembles a miniature handaxe. The sides are not symmetrical, one being straight and the other convex. It may, however, be a broadended scraper such as occurs in the Moustier floor at Ipswich. Patinated white (E.T.L.). (Floor 21).

Fig. $16(\mathrm{H})$. An end scraper with coarse side dressing made from an external flake. The broad end near the bulb is functional, with regular steep work. Blue and white patination (E.T.L.). (Floor 22.)

Fig. $16(\mathrm{~N})$. A good example of a broken Levallois flake with parallel sides. The butt is nearly squared and extensively facetted, the bulb being in one corner ( 3 by $2 \frac{1}{4}$ in.) (A.E.P.). (Floor 22).

Fig. 17 (A). A rare form of tortoise core. (Floor 23). (A.E.P.). It shows the typical boat-shape. The under face shows truncated work. Part of the upper dressed face is retained, and from the other end have been struck two parallel flakes, long and narrow. Long, narrow flakes are not common at the Graves, but the end scraper on a blade is now an established type (Floor 23) (A.E.P.). ( $4 \frac{1}{2}$ by $3 \frac{3}{4}$ in.). 

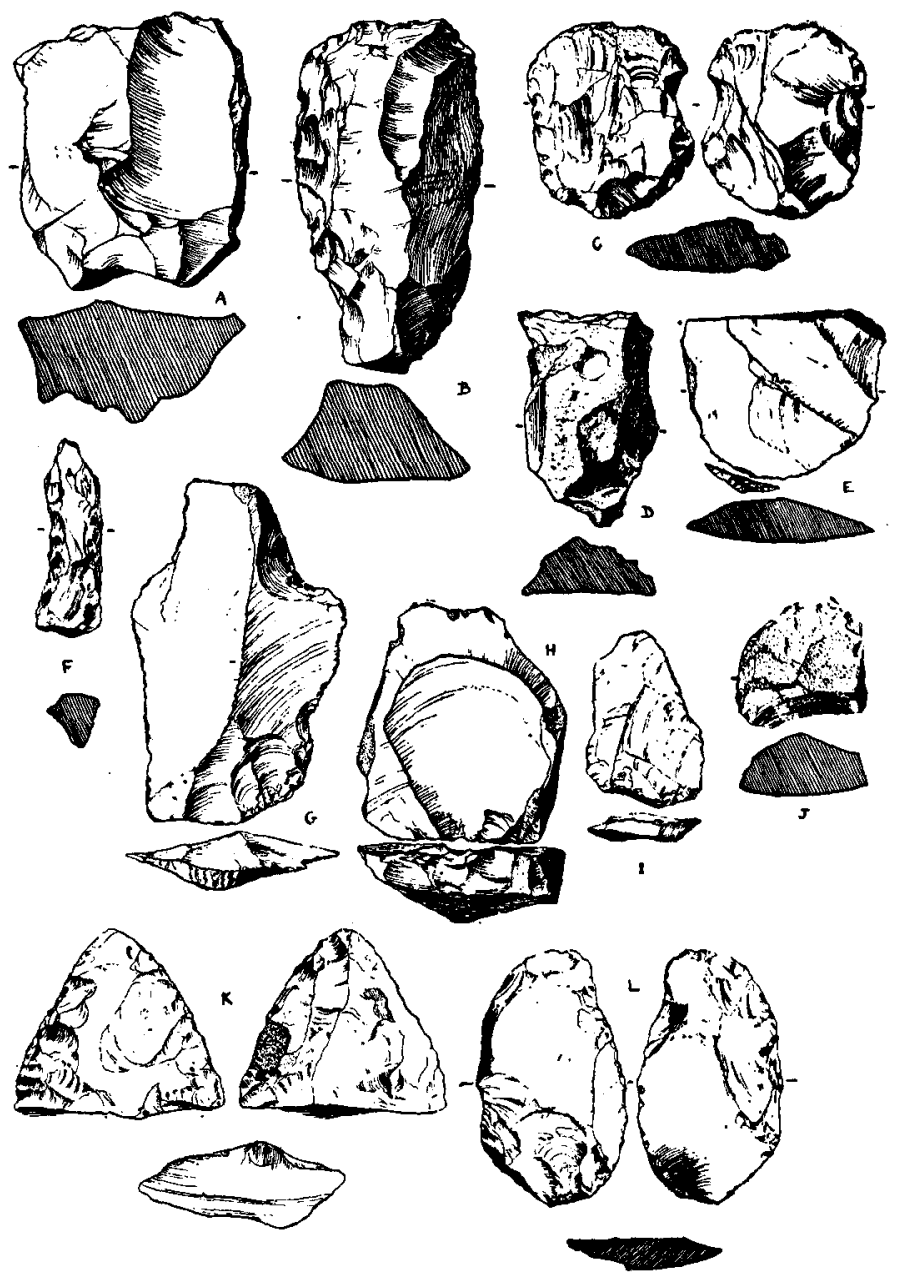

Fig. 17. (A) Tortoise core from which two parallel blades have been struck. Floor XVI. (B) Steep-ended plane with side work. Floor XXIX. (c) Disc, Pit 3. (D) Square-ended scraper with graver spur, Pit 3. (E) Butt end of Northfleet implement with facetted platform, Pit 4. (F) Small pick (West field). (c) Levallois flake with encoche and view of facetted platform. (H) Tortoise core with central scar and no dressing of the upper face, Pit 4. ( 1 ) Small used Levallois flake showing facetted platform, Pit 4. (A.E.P.). (J) Racloir, Pit 5 (E.T.L.). (k) Pointed end of large axe, Pit 4. (L) Racloir of Le Moustier form with facetted platform (West field) (A.E.P.). 


\section{FIOOR 29.}

A little to the South of Pit 1, I located another chipping zone situated on the East fall of a pit. Facetted flakes were very numerous, especially long, narrow pieces converted into implements, which space will not allow me to describe. Three notable pieces came from this floor:-

Fig. $16(0)$. A plane or cone with an unusually shelving, chipped face, undercut above. The margin is finely workedconvex, and the base chipped from the side (4 in. high). Cones from the Graves are very rarely chipped at this angle.

Fig. 17 (B). A massive one-faced implement which may be described as a square-ended plane or a one-faced axe. Like many others it seems to be a composite tool, as the border near the narrow end is worked to make a convex edge for use as a racloir. It resembles fig. 65, G. G. Report (Floor 4) both in size, in the steepness of the end and sides, and in the convex rounding near the handle, which in the new example is narrower (6 in. long) (A.E.P.). White.

Fig. $16(\mathrm{P})$. A thick external flake the free edge of which is used and patinated white like the rest of the surface. The crust shows a number of incised lines resembling the head of a fish, the three principal ones radiating from a common point. It will be recalled that primitive gravers have been recorded from this culture, and an engraved flint figured, Proc., Vol II., p. 433.

Pit 3.

A little to the N.E. of floor 15 I made a section across a new pit (3). In doing so I found that the first $2 \mathrm{ft}$. of soil was packed with chipped flint refuse of the same type as the other floors, the waste of a workman chipping out implements. With this was mixed chalk-rubble and shells, mostly Pomatias elegans and Helix nemoralis. There was also a number of bones of red deer, and one tooth of a carnivorous animal, either fox or dog, and jaw of sheep or goat. There were many steep-faced lumps of various sizes, and two hammers of flint. Facetted flakes were plentiful.

From this layer came two good pieces:-

Fig. 17 (c). A disc made from a crusted flake, patinated white, well chipped on both faces. It has parallel sides and convex ends, and at no part is the edge secondarily worked to produce a cutting or scraping margin. Those who advocate the type known as a throwing stone would include it in that category ( $3 \frac{1}{4}$ by $2 \frac{3}{4}$ in.) (A.E.P.).

Fig. $16(\mathrm{Q})$. The butt end of a typical Northfleet implement. The facets on their upper face show that it was struck from a tortoise core. The platform is facetted, and the surface above the bulb thinned by battered work. One side edge, too, has been trimmed on the upper face. It is still 27 inches long and 3 in. wide. It is somewhat curious how seldom one finds the distal end of these 
implements. In its present form it is a tea-cosy with hinge fractured base, but $I$ believe it is a flake implement broken in half. Patinated white (A.E.P.).

Below this layer the chalk-rubble was finer in texture and crowded with shells, a report on which, by Mr. A. S. Kennard, F.G.S., is appended. Running through this layer, which was $1 \frac{1}{2} \mathrm{ft}$. thick, was a band of charcoal, evidently a hearth, with bones of red deer and remains of a large jar of pottery.

Fig. 17 (D). The only noticeable flint work from this layer was an end scraper, fig. 50. It is made from a thick, crusted flake, and has part of one side and the end steeply worked, leaving a spur at the opposite corner. This spur has a coup-de-burin and the characters of a graver. It is deep blue in colour, tending to white.

Beneath this layer were chalk blocks, part of a tilt from another pit, and occurring sparingly through it some very rough and irregular flakes. Below at $4 \mathrm{ft}$. I found a shed red deer horn, with bez and trez tines complete, and at $\mathbf{5} \mathrm{ft}$. large chalk blocks cenented together.

Two distinct varieties of pottery were found in this hearth :-

(A) A coarse ware with reddish buff facings outside. Mr. Reginald Smith says "more like the fragments found deep at Grime's Graves (see Report) and Cissbury, which seem to be contemporary with the pits. Unlike Bronze Age and the Neolithic ware from Kennet Barrow and Mortlake in British Museum." This ware also occurred on floor 15, and helps to link the floors and the pits.

(B) A hard and coarse heavy black ware, hand made, with smooth but uneven everted lip. This has a line of perforations about an inch below the lip, the holes being $1 \frac{3}{4}$ to 2 inches apart. Mr. Reginald Smith says "is pierced for ornament like Fig. 82 (G. G. Report) but is quite distinct otherwise. Most probably Early Iron age." Sufficient of the rim was found to show that the diameter of the pot was 15 inches. This pottery is much heavier than any found at the Graves.

\section{PIT 4.}

This was situated a little to the S.E. of Pit 1. I made a section in the centre of this pit and found a large collection of flint chipped refuse. It was ultimately carried down for $\mathbf{5} \mathrm{ft}$., and showed the following section :-

Humus and chalk with quantities of flint refuse, $1 \frac{1}{2} \mathrm{ft}$.

Chalk lumps and topstone nodules, $1 \mathrm{ft}$.

Fine chalk rubble full of shells and a small sprinkling of blue and white irregular flakes, $2 \frac{1}{2} \mathrm{ft}$.

No hearth was found. The flakes varied much in size. Many were very large, and there were also patches of tiny flakes left from finishing an implement. Facetted butts were very plentiful, and from the quantity of large flakes left there it was evidently a floor chiefly devoted to flake implements. 
Fig. 17 (E). A good example of the butt end of a Northfleet implement of the familiar tea-cosy form. The platform is finely facetted, and the upper face shows that it was struck from a tortoise core. At present $2 \frac{3}{4}$ inches long and $3 \frac{1}{4}$ inches broad. Probably the complete implement was twice as long (A.E.P.). Patinated white.

Fig. 17 (I). A small example of a Levallois flake with facetted butt, 3 inches long, with signs of use at the edge. I have a large series of small flake implements from the Graves, all of which have the familiar dressing of the platform (A.E.P.).

Fig. 17 (G). A large Levallois flake with dressed platform 5 in. long. Near the butt is a convex trimmed edge, and near the end on the same side a broad encoche (A.E.P.).

In regard to the Levallois flakes of this industry, it is noticeable that the primary work is broad and bold, and the dressing of the block was mainly from the ends and not the sides. The dressed face consequently shows generally two or three large facets. This is a notable difference from the Levallois series from French sites figured by Prof. Commont (L'Industrie Moustérienne), where the whole face is covered by negative impressions. At Baker's Hole, Northfleet, examples of both abound.

Fig. 17 (H). A tortoise core from this site is worthy of illustration. It is part of a crusted block with natural keel. The end has been dressed on the under face and also finished with fine work to have a straight margin. From this a blow has been struck to detach a broad-ended flake 3 inches long and $2 \frac{1}{2}$ inches broad, which would have the facetted platform. No attempt in this case has been made to dress the upper face of the core (A.E.P.).

Fig. $17(\mathrm{~K})$. The pointed end of a large axe of probably the same shape as fig. 26 (G.G. Report). The present piece is 3 inches long and $3 \frac{1}{2}$ inches broad, and the complete implement would be much larger than that found in Pit 1 in 1914. It is made from an external flake, and most of the shaping work is done on the underface. Patinated white (A.E.P.).

PIt 5.

Mr. E. T. Lingwood made a section in the pit adjoining Pit 3, and situated in the same hollow. It proved to be nearly devoid of chipped flints and bones, and no hearth was discovered. One fine implement was found.

Fig. $17(\mathrm{~J})$. This is a racloir with a steep convex edge. The work is continued along the base and between the two is a worked spur. The straight edge is worked all along the under face. The whole is patinated white, the under face destroyed, and has some scratches on the crust. ( $2 \frac{1}{2}$ in. long). One in particular, a cross (X) may be inscribed.

The uprooting of a tree exposed to view a small zone of chipped pieces in the N.E. end of the Graves. From this I recovered a fine celt. 
Fig. 18 (A). This celt in its present form is a new type at the Graves, but is, I think, unfinished. The perfect implement of this type is Fig. 83b, Proc., Vol. II., Pt. 3, found by Mr. L. Armstrong on Floor 15. It is a more complete form of figs. 33 and 59 (G. G. Report), $7 \frac{1}{2}$ inches long. It is made from a large external flake of the Wallstone layer of flint.

The cutting edge is worked on both faces, and oval in section. The pointed end is worked for use as a plane, and the section here is triangular. The under face shows an attempt to work the edge, but the fracture is a bad one, and probably for this reason the
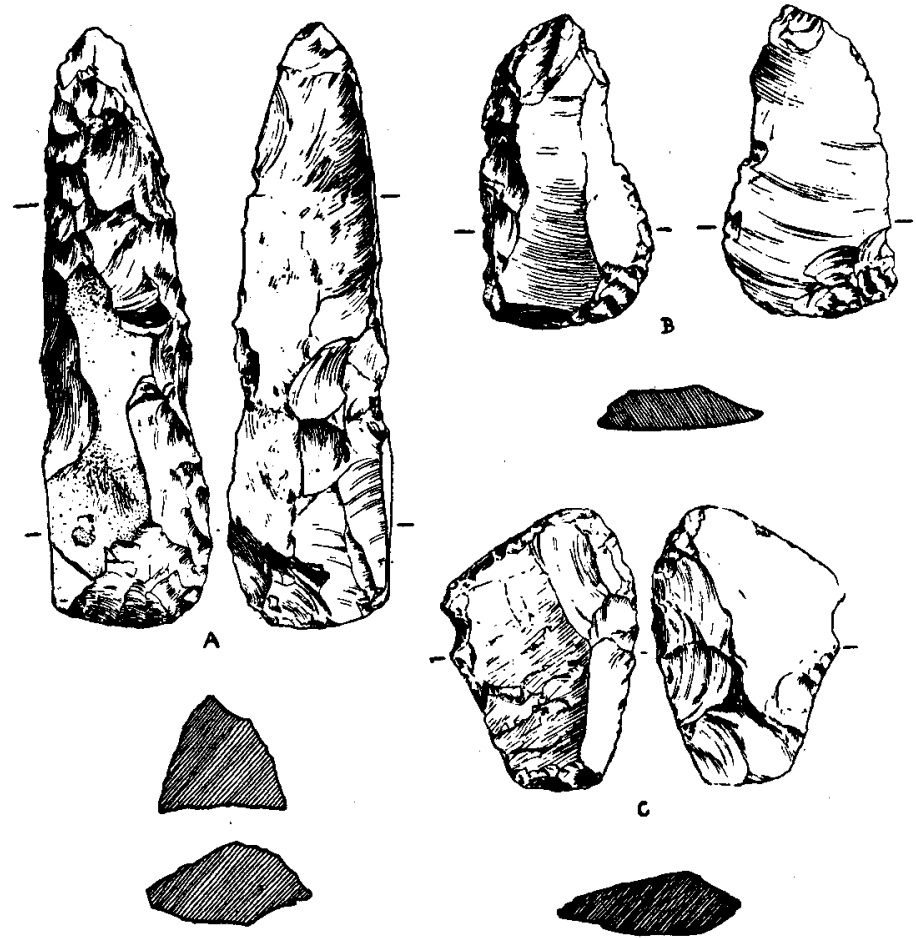

Fig. 18. (A) Celt-like implement. (B) Flake axe (West field). (c) Racloir of Le Moustier form (West field). (A.E.P.). $\frac{1}{3}$

implement was discarded. Patinated white on one face only. Sir J. Evans figures several implements of this form partly or entirely ground, but no examples of ground flint except the flake from floor 16 have been discovered at Grime's Graves.

Fig. 17 (L). A racloir with facetted platform made from a flake struck from a dressed block. The curved edge is trimmed on the under face, and the straighter one on the upper face. White, lustrous and iron-moulded. W. field (A.E.P.) (4 $\frac{1}{8}$ in. long). 
Fig. 18 (c). A racloir with a straight edge. ( $3 \frac{1}{2}$ inches long.) The opposite side edge is trimmed on each face, and the butt is steeply finished. The straight edge terminates in a rounded point (A.E.P.) White. W. field.

Fig. 18 (B). A broad-ended flake converted into a combined racluir and axe with a minimum of work. (4 inches long). A piece of this form could be easily hafted. The broad end has the axe edge completed by half the work being done on one face and half on the other. White. W. field (A.E.P.).

Fig. 17 (F). A small irregular pick with triangular section worked all over the three faces. The butt is a hinge fracture, and probably the implement was originally longer. Mr. Haward exhibited a long, slender implement at the London meeting of the Society, of an entirely new type which has not yet been figured (31 inches.) White. W. field.

The flints illustrated in this paper include five examples of the tortoise core, viz., figs. $13 \mathrm{~F}, \mathrm{G}, \mathrm{I}, 17 \mathrm{~A}$, and $18 \mathrm{H}$. All of these both in size and work are only to be matched from Northfleet and Moustier, and are conclusive evidence that the Moustier method was in use on this site.

Of true Levallois flakes there are three illustrations, viz., figs. $13 \mathrm{C}, 15 \mathrm{G}, 16 \mathrm{Q}$, and $17 \mathrm{E}$, all of which are broken. These are similar in size and work to the Levallois series from Moustier sites, the facetted platforms being particularly typical. A plunging flake is also illustrated to show an accident which frequently occurred when the blow was misdirected. Some examples of racloirs or scrapers are given, two of which still retain the facetted platform. Most of them show a convex scraping edge (figs. $13 \mathrm{~A}, 13 \mathrm{C}, 15 \mathrm{~L}$, $16 \mathrm{~B}, 16 \mathrm{H}, 17 \mathrm{~J}$, and $17 \mathrm{I}$ ). Four examples of the double racloir or "pointe" are given in which the two edges used for scraping are worn by use to form a point. All these are typically Mousterian.

Fig. $14 \mathrm{~F}$ is a borer similar to examples from the caves.

Figs. $14 \%$ and 15 B are steep-side planes, and $16 \mathrm{G}, 16 \mathrm{~K}$, and 160 , steep cone planes nearly allied to the Tarté cones of Aurignac date. Mr. J. Reid Moir found a number of examples of this form on the Moustier level of the floor in Boulton \& Laughlin's pit, Ipswich, and steep-faced cones must now be regarded as a form made in Moustier times.

In the same paper is a celt-like implement of the same date which shows that the celt-like series from the Graves now illustrated are also a Moustier type, viz., figs. $13 \mathrm{H}, 14 \mathrm{~A}, 14 \mathrm{~B}, 14 \mathrm{D}$, $13 \mathrm{I}, 14 \mathrm{G}, 17 \mathrm{~B}, 17 \mathrm{~K}, 18 \mathrm{~A}$, and $18 \mathrm{~B}$. Mr. Reginald Smith, in a paper on the Evolution of the Neolithic Celt (Archooologia, 1917) has shown how the form evolved from the racloir. The disc, fig. $17 \mathrm{C}$, and handaxes, figs. $13 \mathrm{~A}, 13 \mathrm{E}$, and $15 \mathrm{H}$, closely-allied forms, also occur on Moustier sites.

The new evidence from the fints bears out that already published but suggests that the date is nearer Moustier than Aurignac. 
The evidence from the shells (a report on which is appended) is directly opposed to the conclusions derived from a study of the flints, and the whole problem is rendered more puzzling by the identification of the new pottery from a pit as Farly Iron Age. No doubt future work on this and parallel sites will show which view is correct.

\section{REPORT ON THE MOLLUSCA.}

By A. S. Kennard, F.G.S., and B. B. Woodward, F.L.S. of pit:-

Pit 3. Layer of chalky rubble $1-3$ feet below present surface

Vitrina pellucida (Müll.) 1 example.

Vitrea crystallina (Müll.) 3 examples.

Polita sydneyensis (Cox.) 1 example

Polita nitidula (Drap.) 1 example.

Polita pura (Ald.) 1 example.

Arion, Sp. common.

Pyramidula rotundata (Müll.) 6 examples.

Hygromia hispida (Linn.) 2 examples.

Vallonia costata (Müll.) Common.

Vallonia excentrica, Sterki. 2 examples.

Helix nemoralis, Linn. Common.

Helix hortensis, Müll. 2 examples.

Cochlicopa lubrica (Müll). 3 examples.

Pupilla muscorum (Linn.) 6 examples.

Truncatellina minutissima (Hart.) 2 examples

Clausilia bidentata (Ström.) 1 example

Carychium minimum, Müll. Common

Acicula lineata (Drap.) 2 examples

Pomatias elegans (Müll.) 6 examples.

Band formule of Helix nemoralis :-

$$
\begin{aligned}
& \begin{array}{llllll}
1 & 2 & 3 & 4 & 5 & -9 \\
& -9 x a m p l e s .
\end{array} \\
& \left(\begin{array}{lllll}
1 & 2 & 3 & 4 & 5
\end{array}\right)-4 \quad 4 \quad \text {," } \\
& \text { (1 } 2 \text { ) } 3\left(\begin{array}{ll}
4 & 5
\end{array}\right)-2 \text {, } \\
& \left(\begin{array}{lll}
1 & 2 & 3
\end{array}\right)\left(\begin{array}{ll}
4 & 5
\end{array}\right)-1 \text { example } \\
& 1233(45)-3 \text { examples } \\
& \begin{array}{lllllll}
1 & 0 & 3 & 4 & 5 & -2 &
\end{array} \\
& \begin{array}{llllllll}
0 & 0 & 3 & 0 & 0 & -2
\end{array} \\
& \begin{array}{lllllll}
0 & 0 & 0 & 0 & 0 & -3 & -3
\end{array}
\end{aligned}
$$

Band formula of Helix hortensis:-

$\begin{array}{llllll}1 & 2 & 3 & 4 & 5 & -1 \\ & 1 \text { example. }\end{array}$

$\begin{array}{llllll}0 & 0 & 0 & 0 & 0 & -1 \\ 1 & \text { example. }\end{array}$

Pit 4. Chalky rubble $1-3$ feet below present surface.

Vitrina pellucida (Müll.) 4 examples.

Vitrea crystallina (Müll.) Commlon.

Polita pura (Ald.) 6 examples.

Arion, Sp. Common.

Pyramidula rotundata (Müll.) Common.

Hygromia hispida (Linn.) 3 examples. 
Vallonia costata (Müll.) 2 examples. Vallonia excentrica (Sterki.) 2 examples Helicigona lapicida (Linn.) 1 example. Helix nemoralis (Linn.) Common. Helix hortensis (Müll.) 1 example. Cochlicopa lubrica (Müll.) 3 examples. Pupilla muscorum (Linn.) 2 examples. Truncatellina minutissima (Hart.) 1 example.

Clausilia laminata (Mont.) 1 example.

Clausilia bidentata (Ström.) 3 examples.

Carychium minimum (Müll). Common. Acicula lineata (Drap.) 8 examples. Pomatias elegans (Müll.) Common.

Band formula of Helix nemoralis :-

$\begin{array}{llllll}1 & 2 & 3 & 4 & 5 & -2\end{array}$

(1 2 2) $3\left(\begin{array}{lll}4 & 5\end{array}\right)-3 \quad$,

$\left(\begin{array}{lllll}1 & 2 & 3 & 4 & 5\end{array}\right)-2 \quad$,

$\left.\begin{array}{lllll}1 & 2 & 3 & (4 & 5\end{array}\right)-2 \quad$,

$\begin{array}{llllllll}0 & 0 & 3 & 0 & 0 & -2 & 2\end{array}$

$\begin{array}{lllllllll}0 & 0 & 0 & 0 & 0 & -2 & 2\end{array}$

Band formula of Helix hortensis :-

$\begin{array}{lllll}0 & 0 & 0 & 0 & 0\end{array}$

These two lists are practically identical, and the facies is that of the fauna obtained from the deposits within the shafts. The whole assemblage denotes much damper conditions than now exist. This additional evidence confirms the view previously expressed by us that Grime's Graves were excavated in the damp period immediately succeeding the first warm Holocene period, i.e., the lower Turbarian of the late Prof. James Geikie.

Mr. Reginald Smith, F.S.A., has kindly made the following notes on the pottery found last year at Grime's Graves:-

(1) Heavy lip of a corn-bin or storage jar of some kind, is not far removed from Silchester specimens at Reading, and may be just pre-Roman, but can hardly be connected with the Bronze Age or earlier wares. Found by Mr. A. L. Armstrong 9 inches below the surface on Floor 16.

(2) The rim (ornamented with finger-nail pattern), side, and

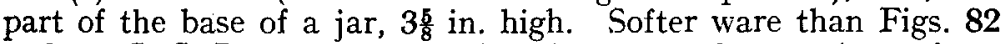
and 83, G. G. Report, but probably the same culture. Apart from surroundings I should say Early Iron Age. Floor 15.

(3) Part of lip of vessel of thick ware with slightly outstanding lip. "Apparently of the same date as figs. 82 and 83, G. G. Report, but softer variety of paste." $1 \frac{1}{2}$ in. thick. Floor 15.

(4) Part of rim of vessel with buff facings and everted lip. "The shape of the lip is far from primitive; for the ware as well as the finger-nail ornament compare G. G. Report, fig. 83." Perhaps Early Iron Age.

(5) Portions of the side and base of a vessel of coarse ware. Base 8 in. thick. This portion of the base is 4 inches across, and the whole vessel would be quite 8 inches in diameter at the base. 
"This group with reddish buff facings outside is more like the fragments found deep at Grime's Graves (1914) and Cissbury, which seem to be contemporary with the pits. Unlike Bronze Age and the Neolithic ware from Kennet Barrow and Mortlake in British Museum." Floor 15.

(6) "Part of a flat base with large grid. Fairly hard ware. ? date." Floor 15.

(7) "Part of wall of urn, soft ware with yellow facing, perhaps a variety of figs. 82 and 83." Floor 15.

(8) Part of rim of vessel $\frac{1}{2}$ inch thick. Rim vertical with horizontal thumb pad impressions. Perforations $\frac{1}{4}$ inch in diameter, 1 inch apart, and $\frac{1}{2}$ inch below lip. Incised horizontal and crossed pattern." Compare Report, fig. 82. Not like Bronze Age ware, possibly earlier, but most likely Early Iron Age. Floor 16.

(9) Vertical side with part of rim ; squared top.

Part of shouldered side with rim having thumb pad impressions on the lip.

"Two harder fragments, probably of same character as figs. 82 and 83 , but shapes are problematical."

(10) Rim of vessel with yellow facings and wall $\frac{3}{4}$ inch thick. "This group is unlike Bronze Age ware, which should be ornamented when of this size." Floor 15.

(11) Part of the side of a vessel with reddish facing. The outside is ornamented with finger-nail impressions to form a leaf pattern.

"This is more like Bronze Age ware, but the ornament is unusual. Rather coarse. The lip notching is found on several Bronze Age types." 